\title{
BMJ Open Final results from the Betaseron (interferon $\beta-1 b)$ Pregnancy Registry: a prospective observational study of birth defects and pregnancy-related adverse events
}

\author{
P K Coyle, ${ }^{1}$ S M Sinclair, ${ }^{2}$ A E Scheuerle, ${ }^{3} \mathrm{~J}$ M Thorp Jr, ${ }^{4} \mathrm{~J}$ D Albano, ${ }^{5}$ \\ M J Rametta ${ }^{6}$
}

To cite: Coyle PK, et al. Final results from the Betaseron (interferon $\beta$-1b) Pregnancy Registry: a prospective observational study of birth defects and pregnancy-related adverse events. BMJ Open 2014;4 e004536. doi:10.1136/ bmjopen-2013-004536

- Prepublication history for this paper is available online. To view these files please visit the journal online (http://dx.doi.org/10.1136/ bmjopen-2013-004536).

Received 22 November 2013 Revised 4 April 2014 Sinclair SM, Scheuerle AE, Accepted 9 April 2014

\section{ABSTRACT}

Objective: Women with multiple sclerosis are often diagnosed and treated during their reproductive years. Limited data are available on the safety of treatment during pregnancy. The Betaseron Pregnancy Registry prospectively monitored women exposed to interferon $\beta-1 \mathrm{~b}$ (IFN $\beta$-1b) during pregnancy to estimate the rates of birth defects, spontaneous abortions (SABs) and other negative outcomes in this population.

Design: From 2006 to 2011, this observational registry enrolled women exposed prior to conception or during pregnancy (but prior to or without abnormalities on prenatal screening). Follow-up continued from enrolment through the 4-month paediatric visit. Setting: Patients in the USA who met these criteria were enrolled in the registry.

Results: The registry enrolled 99 pregnant women; 3 were lost to follow-up. The earliest exposure to IFN $\beta$-1b occurred during the first trimester for 95 pregnancies and in the third trimester for 1 pregnancy. There were 99 birth outcomes ( 3 twins), including $86(86.9 \%)$ live births, $11(11.1 \%)$ SABs and $2(2 \%)$ stillbirths. Birth defects were reported in five (5.1\%) cases. Rates of birth defects and SAB were not significantly different from population comparators. No developmental concerns were identified at the 4-month paediatric visit.

Conclusions: The small sample size limits the ability to draw definitive conclusions; however, there was no pattern to suggest increased negative outcomes with IFN $\beta$-1b.

Clinical trials registration number: NCT00317564.

\section{INTRODUCTION}

For numbered affiliations see end of article.

Correspondence to

Dr Patricia Coyle;

patricia.coyle@

stonybrookmedicine.edu
Multiple sclerosis (MS) is a chronic demyelinating and neurodegenerative disorder that affects over 400000 people in the USA. ${ }^{12}$ MS is much more common in women than men, and diagnosis frequently occurs when patients are in their $20 \mathrm{~s}$ and $30 \mathrm{~s}^{3}{ }^{4}$

\section{Strengths and limitations of this study}

- The Betaseron Pregnancy Registry contains the largest sample of interferon $\beta-1 b$-exposed pregnancies collected to date.

- The relatively small sample size limits the ability to draw definitive conclusions; however, there was no pattern to suggest increased negative outcomes with interferon $\beta-1 b$.

- Limitations of the Betaseron Pregnancy Registry include the potential for under-reporting or differential reporting of outcomes due to the exclusion of retrospective patients and the voluntary nature of participation.

- Birth defect ascertainment was limited to data obtained from reporting healthcare providers; infants were not examined directly as part of the registry.

- Data on infant outcomes were only collected for up to 4 months, reducing the ability of the registry to measure developmental progress, defects diagnosed beyond 4 months of age, and resolution of suspected defects reported in early infancy.

Consequently, women of childbearing age constitute a considerable portion of all patients with MS. Furthermore, up to $10 \%$ have disease onset during pregnancy. ${ }^{1}$

The approved disease-modifying treatments (DMTs) for patients with MS have been given pregnancy category ratings of $\mathrm{B}, \mathrm{C}, \mathrm{D}$ or $\mathrm{X}$ by the US Food and Drug Administration (FDA) based on clinical experience and/or preclinical data (see table 1 for pregnancy categorisations of currently approved DMTs and a definition of different pregnancy classifications). ${ }^{5-14}$ The safety of these agents during pregnancy is a major concern given the patient profile outlined above. However, data on pregnancy outcomes in DMT-exposed patients are limited. Among the $\beta$ interferons, 
Table 1 Pregnancy classifications of disease-modifying treatments (DMTs) approved for use by patients with multiple sclerosis

\section{Disease-modifying therapy}

Pregnancy category

Glatiramer acetate (Copaxone) ${ }^{9}$

\section{B}

Interferon $\beta$-1b (Betaseron/Betaferon; Extavia) ${ }^{5} 14$

C

Intramuscular interferon $\beta-1$ a (Avonex) ${ }^{7}$

Subcutaneous interferon $\beta$-1a (Rebif) ${ }^{11}$

Fingolimod (Gilenya) ${ }^{8}$

Dimethyl fumarate (Tecfidera) $)^{13}$

Natalizumab (Tysabri) ${ }^{6}$

Mitoxantrone ${ }^{6} 10$

Teriflunomide (Aubagio) ${ }^{6} 1012$

FDA pregnancy categories ${ }^{15}$

- Category A: No evidence of adverse effects in studies of pregnant humans

- Category B: No studies from humans, but no evidence of adverse effects in studies of pregnant animals; or negative effects observed in animal models but no evidence of adverse effects in humans

- Category C: Insufficient evidence from human studies, but research with pregnant animals identified some medication-related negative outcomes; in some situations, the medication may be more beneficial than harmful

- Category D: Medication-related negative outcomes in human studies but medication may be needed in some situations

- Category X: Medication-related negative outcomes in human or animal studies; there are no situations in which the medicine should be used

this is particularly true for interferon $\beta-1 b$ (Betaseron/ Betaferon; Bayer HealthCare Pharmaceuticals; Whippany, New Jersey, USA).

No teratogenic effects were seen in studies of pregnant rhesus monkeys exposed to interferon $\beta-1 \mathrm{~b}$. However, dose-related abortifacient activity was seen at doses from $0.028 \mathrm{mg} / \mathrm{kg} /$ day to $0.42 \mathrm{mg} / \mathrm{kg} /$ day, which is $2.8-4.0$ times the recommended human dose based on surface area comparison. ${ }^{5}$ Although data on human exposure during pregnancy are limited, patients are advised to discontinue treatment with interferon $\beta-1 b$ if they become pregnant or plan to become pregnant. ${ }^{5}$ The goal of the Betaseron Pregnancy Registry was to compare pregnancy outcomes in women exposed to interferon $\beta-1 b$ at conception or during pregnancy relative to general population comparators. This is the largest observational study reported to date for interferon $\beta-1 b$.

\section{METHODS}

\section{Population and outcome measures}

The Betaseron Pregnancy Registry was a voluntary, prospective, observational, exposure registration and follow-up study. Women with an existing pregnancy who had been exposed to interferon $\beta-1 \mathrm{~b}$ at any time after the first day of the last menstrual period (LMP), or during pregnancy but before any prenatal screening (eg, ultrasound and amniocentesis), were prospectively enrolled in the registry. Women with similar exposure who had undergone some prenatal testing and were without abnormal findings suggestive of fetal abnormalities were also enrolled. Given the widespread use of early prenatal testing, restricting enrolment to women without prenatal testing would have dramatically reduced the available population, hindering the success of the registry. ${ }^{16}{ }^{17}$ As retrospective cases (ie, pregnancies submitted after the birth of the infant or after evidence suggestive of an abnormality on prenatal tests) can be biased towards reporting of unusual or severe outcomes, these cases and those in which an abnormality was identified prior to registry contact were excluded.

The primary outcome measure was the rate of major congenital malformations in infants exposed to interferon $\beta-1 b$ during gestation, defined as any time after the first day of the mother's LMP. Secondary outcome measures included the prevalence of spontaneous abortion and other negative pregnancy outcomes in exposed women. The prevalence of elective abortion, stillbirth, ectopic pregnancy, neonatal death and maternal death was assessed. Reporting was conducted by healthcare providers (HCPs), patients or representatives of the study sponsor. Maternal follow-up lasted from enrolment through pregnancy outcome. Infant follow-up continued through the 4-month paediatric visit in most cases.

Pregnancy outcomes were classified as live birth, spontaneous abortion, elective abortion or fetal death/ stillbirth. A live birth was defined as any delivery resulting in a viable neonate $\geq 24$ weeks of gestation. The spontaneous loss of a fetus at $<20$ weeks of gestation was classified as a spontaneous abortion. Any fetus delivered dead $\geq 20$ weeks of gestation, or weighing $\geq 500$ g regardless of gestational age, was classified as a stillbirth. Fetal death occurring $>20$ weeks but $<28$ weeks was classified as early fetal loss while death occurring $\geq 28$ weeks was considered late fetal loss. Elective abortions encompassed any induced or voluntary ending of the pregnancy. Other pregnancy outcomes included ectopic pregnancies, maternal death and neonatal death. Infant size was classified as 'small', 'appropriate' or 'large' for gestational age based on HCP assessment. 
Birth defects were defined as any significant structural or chromosomal defect diagnosed with signs/symptoms using the Metropolitan Atlanta Congenital Defects Program (MACDP) classification of birth defects, or any case with two or more secondary or 'conditional' abnormalities that would not have been classified as primary birth defects by the MACDP. Conditional abnormalities, some of which were also referred to as 'minor birth defects', were included if present in a cluster of two or more to increase the sensitivity of monitoring and to avoid missing a potential signal. Birth defects were coded using an organ system classification to increase the possibility of detecting a potential signal by grouping together similar defects or defects with similar aetiology. ${ }^{18}$ All cases were coded in accordance with the MACDP code book and the organ system classification by an expert in dysmorphology (AES) who evaluated the potential temporal relationship between the exposure to interferon $\beta-1 b$ and the aetiology of the defect, considering other potential confounders (eg, exposure to other therapies received during the pregnancy, maternal or paternal history of defects, underlying disease). ${ }^{18}$ Further follow-up for birth defect cases was conducted if additional information was needed by the dysmorphologist or the data safety monitoring board (DSMB). Defects were classified as 'defect with a known cause, temporality may be irrelevant'; 'no temporal association' or 'unable to assess temporality'. Available data for each defect case were reviewed individually for potential confounders and relevant information was evaluated and recorded.

Conduct of the registry was overseen by an independent DSMB. The Betaseron Pregnancy Registry was listed in the public trials registry (http://www.clinicaltrials. gov) under NCT00317564.

\section{Statistical procedures}

Analyses were conducted on all prospective evaluable cases (ie, enrolled pregnancies, not lost to follow-up, with known outcome and birth defect status). The birth defect rate was calculated by dividing the number of cases with birth defects among all live births and fetal losses $>20$ weeks gestation (numerator) by the number of live births (denominator). This approach increased the sensitivity of monitoring and may have overestimated the true rate; however, it erred on the side of caution. Since the presence or absence of birth defects is difficult to ascertain among fetal losses, including fetal losses in the denominator would have biased the birth defect rate downwards. Ninety-five per cent exact CI were calculated for birth defect rate and other point estimates. Outcome data were stratified by the earliest trimester of exposure to interferon $\beta-1 b$.

Population-based external comparator groups were used to evaluate the rates of spontaneous abortion and birth defects in the registry. Risk of spontaneous abortions was compared with estimates for the general population of the USA from the National Survey of Family Growth (NSFG), which was conducted by the National Center for Health Statistics, ${ }^{19}$ using Fisher's exact test based on binomial distribution for exposures. Risk of birth defects was compared with that reported by the MACDP. $^{2021}$ This population-based birth defect surveillance system includes all infants born in the metropolitan area of Atlanta, Georgia. From 1999 to 2003, the MACDP estimated the population birth defect rate to be 2.78 birth defects/100 live births in its database..$^{20}$

When the registry was designed and launched, it aimed to enrol approximately 420 pregnant women to reach the goal of 210 live births to evaluate the primary endpoint (risk of birth defects). This sample size was estimated to be sufficient to rule out a 2.2-fold increase in birth defects compared with the MACDP rate of $2.78^{2021}$ with $80 \%$ power (assuming a $5 \%$ level of significance). The sample size goal of 420 pregnancies was expected to result in only 210 live births because of losses to follow-up, enrolment failures and a live birth rate of $62 \% .{ }^{17}$ After approximately 5 years of operation, registry enrolment resulted in only 99 live births.

\section{Role of the funding source}

The study was jointly designed by members of the DSMB and the study sponsor. The authors, which included the DSMB and representatives of the sponsor, had access to all the data, participated in analysis and interpretation, and were members of the publication committee. The decision to submit the article for publication was made jointly by the members of the steering committee and the sponsor.

\section{RESULTS}

\section{Patient disposition}

Between 24 April 2006 and 31 July 2011, 99 pregnant women were prospectively enrolled in the Betaseron Pregnancy Registry. Follow-up of pregnant women and their live-born infants continued through 16 July 2012. Pregnancy outcomes were reported for 96 exposed pregnancies, with 3 pregnancies lost to follow-up (table 2). Initial exposure to interferon $\beta-1 b$ occurred in the first trimester for 95 patients, and in the third trimester for 1 patient. Seventy-four patients had paediatric follow-up. For the remaining 22 patients, follow-up continued only until birth. Prenatal testing prior to enrolment was reported in 33 cases $(34.4 \%)$.

The majority of the sample was Caucasian (62 patients $(64.6 \%)) ; 25$ patients (26\%) were African-American. In addition, two patients $(2.1 \%)$ were Hispanic while six patients were of other races/ethnicities (6.3\%) and race/ethnicity data were missing for one patient $(1 \%)$. Note that the distribution of race/ethnicity in the Betaseron Pregnancy Registry was different from population norms in the USA $(72.4 \%$ Caucasian, $12.6 \%$ African-American, $16.3 \%$ Hispanic). ${ }^{22}$

\section{Pregnancy outcomes}

From the 96 evaluable pregnancies, there were a total of 99 birth outcomes available, including 3 sets of twins. 
Table 2 Maternal demographics

\begin{tabular}{|c|c|}
\hline & $\begin{array}{l}\text { Analysis } \\
\text { population } \\
(\mathrm{N}=96)\end{array}$ \\
\hline \multicolumn{2}{|l|}{ Age at enrolment (years) } \\
\hline $\mathrm{n}$ & $95^{*}$ \\
\hline Mean (SD) & $30.9(5.29)$ \\
\hline Median (range) & $31.0(19-44)$ \\
\hline \multicolumn{2}{|l|}{ Age category, $\mathrm{n}(\%)$, years } \\
\hline$\leq 19$ & $1(1.0)$ \\
\hline $20-34$ & 69 (71.9) \\
\hline$\geq 35$ & $25(26.0)$ \\
\hline Missing & $1(1.0)$ \\
\hline \multicolumn{2}{|l|}{ Race/ethnicity, n (\%) } \\
\hline White & $62(64.6)$ \\
\hline Black & $25(26.0)$ \\
\hline Hispanic & $2(2.1)$ \\
\hline Asian & $0(0)$ \\
\hline Other & $6(6.3)$ \\
\hline Missing & $1(1.0)$ \\
\hline \multicolumn{2}{|l|}{ MS duration at enrolment, $\mathrm{n}(\%)$, years } \\
\hline$<1$ & $23(24.0)$ \\
\hline $1-5$ & $51(53.1)$ \\
\hline $6-10$ & $11(11.5)$ \\
\hline$>10$ & $6(6.3)$ \\
\hline Missing & $5(5.2)$ \\
\hline \multicolumn{2}{|l|}{ Earliest trimester of exposure, $\uparrow n(\%)$} \\
\hline First & $95(99.0)$ \\
\hline Second & $0(0)$ \\
\hline Third & $1(1.0)$ \\
\hline \multicolumn{2}{|l|}{ Prenatal tests, n (\%) } \\
\hline Prenatal test(s) after enrolment & $53(55.2)$ \\
\hline Prenatal test(s) prior to enrolment & $33(34.4)$ \\
\hline Date of prenatal test(s) not provided & $1(1.0)$ \\
\hline No prenatal tests & 7 (7.3) \\
\hline Missing/unknown & $2(2.1)$ \\
\hline \multicolumn{2}{|c|}{$\begin{array}{l}{ }^{*} \text { Age data were missing for one case. } \\
\text { †First trimester exposure was initial exposure occurring from the } \\
\text { first day of the LMP through } 13 \text { weeks gestation; third trimester } \\
\text { exposure was initial exposure occurring in the } 28 \text { th week through } \\
\text { the end of the pregnancy. } \\
\text { LMP, last menstrual period; MS, multiple sclerosis. }\end{array}$} \\
\hline
\end{tabular}

These outcomes included 86 live births, 2 stillbirths and 11 spontaneous abortions (table 3). Both stillbirths occurred in black women with a history of prior spontaneous abortion and other comorbidities that may have affected birth outcomes. The first case, ending in stillbirth, reported hypertension, obesity (postgastric bypass) and oligohydramnios. The second reported antiphospholipid antibody syndrome, maternal human papillomavirus infection, early rupture of membranes attributed to vaginal bacterial infection and preterm labour and delivery attributed to incompetent cervix. The prevalence of spontaneous abortion in the Betaseron Pregnancy Registry $(11.5 \%$ (95\% CI 5.9 to 19.6) ) was not significantly different from the $16 \%$ estimate for the general population of the USA based on NSFG data (relative risk 0.7 (95\% CI 0.4 to 1.2 ), $\mathrm{p}=0.86$; Fisher's exact test based on binomial distribution for exposures).

Infant assessments were made at birth for 86 babies, up to 3 months of age for 74 babies and at 4 months for 59 babies (table 4). HCPs assessed infant size as appropriate for gestational age at birth for 67 cases $(77.9 \%)$. Four-month follow-up did not identify any consistent pattern of developmental abnormalities. Birth defects were identified in five cases (table 5), resulting in a relative risk of 2.1 (95\% CI 0.9 to 4.9 ). The reported birth defects occurred in several different organ systems, including the musculoskeletal, cardiovascular and circulatory systems, with no pattern to the organ systems affected. For all cases reporting birth defects, the earliest exposure to interferon $\beta-1 \mathrm{~b} 250 \mu \mathrm{g}$ dosed every other day occurred during the first trimester of gestation. No birth defects were reported among the spontaneous pregnancy losses or stillbirths. The birth defect rate estimated by the Betaseron Pregnancy Registry $(5.8 \%$ (95\% CI $1.9 \%$ to $13.0 \%$ )) was not significantly different from that reported by the MACDP $(2.78 \%, \mathrm{p}=0.092$, Fisher's exact test). The relatively wide CIs, which include the MACDP rate, reflect the small sample size and suggest

Table 3 Pregnancy outcomes in the Betaseron Pregnancy Registry

\begin{tabular}{|c|c|c|}
\hline Outcomes, n (\%, 95\% Cl) & Interferon $\beta$-1b-exposed pregnancies & Relative risk (95\% Cl) \\
\hline Live births $(\mathrm{N}=96)$ & $83(86.4)$ & - \\
\hline Birth defects $(\mathrm{N}=86)^{*}$ & $5(5.8,1.9$ to 13.0$)$ & 2.1 (0.9 to 4.9$), p=0.092 \dagger$ \\
\hline Spontaneous abortions $(\mathrm{N}=96)$ & $11(11.5,5.9$ to 19.6$)$ & 0.7 (0.4 to 1.2$), p=0.8603 \ddagger$ \\
\hline Stillbirth $(\mathrm{N}=96)$ & $2(2.1)$ & - \\
\hline Maternal deaths & $0(0)$ & - \\
\hline Infant deaths & $0(0)$ & - \\
\hline Ectopic pregnancies & $0(0)$ & - \\
\hline
\end{tabular}


no difference between the birth defect rate from the Betaseron Pregnancy Registry and the MACPD.

Owing to the relatively high percentage of black patients in the Betaseron Pregnancy Registry, a subanalysis of pregnancy outcome data was conducted to compare black and non-black patients. No significant differences were seen between these two populations in the rates of birth defects or rates of spontaneous abortion. However, small sample sizes in this subanalysis limit the conclusions that can be drawn from these data.

\section{DISCUSSION}

This Betaseron Pregnancy Registry reported 99 outcomes in 96 evaluable pregnancies (including 3 twin pregnancies), consisting of 86 live births, 2 stillbirths and 11 spontaneous abortions. There were five cases with birth defects. Among these five cases were a variety of birth defects which were not clustered around a single type of defect or effected organ system. In addition, two of these cases had defects that were not temporally related to interferon $\beta-1 b$ exposure (ie, the timing of the exposure was not consistent with the development of the defect) and one had a chromosomal abnormality potentially related to advanced maternal age that was classified as having no temporal association to exposure. This lack of consistent pattern suggests that there was no signal for birth defects due to interferon $\beta-1 b$ exposure. The risk of spontaneous abortion or birth defect was not significantly different from comparator populations. In addition, no elective abortions or maternal deaths were observed and there were no abnormalities in rate of prematurity or in birthweight/ size. These data represent the largest cohort of interferon $\beta$-1b-exposed patients reported to date; however, the sample size was still smaller than necessary to have sufficient statistical power to draw definitive conclusions.

To date, several publications have discussed the results of exposure to interferon $\beta$ formulations during pregnancy; however, none have exclusively examined interferon $\beta-1 b$ exposure. A recent review of this literature suggested that $\beta$ interferons may be associated with some negative outcomes, ${ }^{26}$ a conclusion that contrasts with the findings presented here. Three studies, also with small sample sizes ( $\mathrm{N}=88,69$ and 23), found low birthweight in infants exposed to interferon $\beta$ formulations (either interferon $\beta$-1a or $\beta-1 b)$ during gestation. ${ }^{27-29}$ Another study $(\mathrm{N}=14)$ found evidence of prematurity with interferon $\beta$ exposure, but birthweight was not significantly lower than unexposed comparators. ${ }^{30}$ However, another study $(\mathrm{N}=63)$

Table 4 Infant assessments at birth and at 4 months

\begin{tabular}{|c|c|c|c|}
\hline & At birth & At 4-month follow-up & $\begin{array}{l}\text { Approximate median in } \\
\text { US population at birth }\end{array}$ \\
\hline Number of infants & 86 & 59 & \\
\hline \multicolumn{4}{|l|}{ Sex, n (\%) } \\
\hline Female & $40(46.5)$ & $26(44.1)$ & \\
\hline Male & $46(53.5)$ & $33(55.9)$ & \\
\hline \multicolumn{4}{|l|}{ Infant weight, g } \\
\hline Median & 3346.8 & 6747.0 & $3200-3600$ \\
\hline Range & $470.0-4593.0$ & $4763.0-8902.0$ & \\
\hline \multicolumn{4}{|l|}{ Infant size, $\mathrm{n}(\%)^{*}$} \\
\hline Small & $7(8.1)$ & $3(5.1)$ & \\
\hline Appropriate & 67 (77.9) & $48(81.4)$ & \\
\hline Large & $7(8.1)$ & $6(10.2)$ & \\
\hline Missing & $5(5.8)$ & $2(3.4)$ & \\
\hline \multicolumn{4}{|l|}{ Infant length, $\mathrm{cm}$} \\
\hline Median & 50.8 & 63.5 & $49-50$ \\
\hline Range & $30.5-55.9$ & $53.3-69.3$ & \\
\hline \multicolumn{4}{|c|}{ Infant head circumference, $\mathrm{cm}$} \\
\hline Median & 34.3 & 41.9 & $34.8-35.8$ \\
\hline Range & $29.5-38.1$ & $37.0-44.5$ & \\
\hline \multicolumn{4}{|c|}{ Gestational age at birth, weeks } \\
\hline Median & 39.0 & NA & \\
\hline Range & $24.0-41.0$ & NA & \\
\hline \multicolumn{4}{|c|}{ Gestational age at birth, $\mathrm{n}(\%) \dagger \ddagger$} \\
\hline Preterm & $8(10.0)$ & NA & $9.9 \%$ \\
\hline Term & $72(90.0)$ & NA & \\
\hline \multicolumn{4}{|c|}{$\begin{array}{l}\text { *Infant size relative to gestational age at birth and age at } 4 \text { months ( } \pm 4 \text { weeks), respectively. } \\
\text { tGestational age at birth calculated as ( }(280-(\text { corrected estimated due date-outcome date) }) / 7) \text {; EDD was used when corrected EDD was not } \\
\text { available. Preterm births were defined as any baby born before the end of the } 36 \text { th gestational week and term births were defined as those } \\
\text { born after } \geq 37 \text { weeks, } 0 \text { days gestation. }{ }^{25} \\
\ddagger \text { Among singleton live births; excludes three twin pregnancies ( } 6 \text { live births) with outcomes at } 24 \text { weeks, } 5 \text { days; } 36 \text { weeks, } 3 \text { days; and } \\
36 \text { weeks, } 5 \text { days. } \\
\text { EDD, estimated due date; NA, not applicable. }\end{array}$} \\
\hline
\end{tabular}


Table 5 Summary of birth defect cases

\begin{tabular}{|c|c|c|c|}
\hline Case & Description of the reported birth defects ${ }^{\star}$ & Organ system & Temporality assessment \\
\hline \multirow[t]{2}{*}{1} & Live infant, male, 34 weeks gestation & & \\
\hline & Trisomy 21 (Down syndrome)† & Chromosome anomaly & $\begin{array}{l}\text { Defect with known cause, temporality } \\
\text { may be irrelevant }\end{array}$ \\
\hline \multirow[t]{2}{*}{2} & Live infant, male, 40 weeks gestation & & \\
\hline & $\begin{array}{l}\text { Haemangioma (capillary haemangioma parietal } \\
\text { area and left third toe) }\end{array}$ & Circulatory system & Unable to assess temporality \\
\hline \multirow[t]{5}{*}{3} & Live infant, female, 39 weeks gestation & & \\
\hline & Hip dysplasia (defect) & $\begin{array}{l}\text { Other musculoskeletal } \\
\text { defects }\end{array}$ & Unable to assess temporality \\
\hline & Patent foramen ovale (conditional defect) & Heart & $\begin{array}{l}\text { Defect with known cause, temporality } \\
\text { may be irrelevant }\end{array}$ \\
\hline & Patent ductus arteriosus (conditional defect) & Circulatory system & $\begin{array}{l}\text { Defect with known cause, temporality } \\
\text { may be irrelevant }\end{array}$ \\
\hline & Ventriculoseptal defect (defect) & Heart & $\begin{array}{l}\text { Defect with known cause, temporality } \\
\text { may be irrelevant }\end{array}$ \\
\hline \multirow[t]{2}{*}{4} & Live infant, male, 36 weeks gestation & & \\
\hline & $\begin{array}{l}\text { Abnormal shape of the head without } \\
\text { craniosynostosis }\end{array}$ & Musculoskeletal defects & No temporal association \\
\hline \multirow[t]{2}{*}{5} & Live infant, male, 38 weeks gestation & & \\
\hline & Polydactyly & $\begin{array}{l}\text { Limb reduction/addition } \\
\text { defects }\end{array}$ & No temporal association \\
\hline
\end{tabular}

did not find evidence of low birthweight following interferon $\beta$ exposure. ${ }^{31}$ Other negative pregnancy outcomes, including a higher rate of spontaneous abortion and shorter mean birth length, have also been associated with exposure to interferon $\beta$ formulations. ${ }^{27} 28$

In contrast, the Betaseron Pregnancy Registry did not find any patterns to suggest negative pregnancy outcomes associated with interferon $\beta-1 \mathrm{~b}$ exposure. It should be noted that the five aforementioned studies combined participants exposed to either interferon $\beta-1 \mathrm{a}$ or $\beta-1 \mathrm{~b}$ into a single group. ${ }^{27-31}$ Two of these studies did not provide separate numbers of interferon $\beta$-1a-exposed and $\beta$-1b-exposed patients. ${ }^{27}{ }^{29}$ In the three studies that divided exposure groups into interferon $\beta-1 \mathrm{a}$ and $\beta-1 \mathrm{~b}$, patients with interferon $\beta-1 \mathrm{~b}$ monotherapy exposure numbered only $10-21,{ }^{28} 3031$ thereby limiting the statistical power to draw conclusions about the effects of interferon $\beta-1 b$ on pregnancy outcomes. The Betaseron Pregnancy Registry data reported here have the advantage of a much larger sample size (99 outcomes), albeit much lower than planned when the registry was designed.

The Betaseron Pregnancy Registry included paediatric follow-up, which has not been consistently reported in other studies: only two other studies have assessed paediatric outcomes. ${ }^{27} 30$ The first $(\mathrm{N}=14)$ reported normal development of interferon $\beta$-1a-exposed or $\beta$-1b-exposed infants up to the 12-month milestones (walking and talking) ${ }^{30}$ A later study $(\mathrm{N}=88)$ found no developmental abnormalities in interferon $\beta$-exposed infants after 2.1 years of follow-up. ${ }^{27}$ The Betaseron Pregnancy Registry's findings are consistent with these previous reports and reinforce the hypothesis that there are no obvious postnatal effects from in utero interferon $\beta-1 b$ exposure.

The potential risks associated with interferon $\beta-1 \mathrm{~b}$ exposure during pregnancy, which were not found to be significantly different from comparator cohorts in this study, need to be considered along with the risks for patients with MS who remain untreated during pregnancy. Prior research suggested that MS itself was not associated with increased risk for negative pregnancy outcomes. ${ }^{1}$ However, risk for relapses is higher after delivery, with $20-40 \%$ of patients experiencing a clinical relapse or worsening of the disease in the first 3 months postpartum. ${ }^{1}$

The results reported here are similar to two recent presentations related to intramuscular interferon $\beta$-1a exposure during pregnancy. In the first, no pattern suggestive of increased negative outcomes was found in 306 pregnancies in the Avonex Pregnancy Exposure Registry. ${ }^{32}$ Similarly, postmarketing surveillance $(\mathrm{N}=552)$ found that the rate of spontaneous abortion was consistent with the general population, with no evidence of increased birth defect rates. ${ }^{33}$ Together with the Betaseron Pregnancy Registry, the preponderance of data suggest no pattern of increased negative outcomes for women and infants exposed to interferon $\beta$ formulations during pregnancy, a finding that was supported by a recent review of the literature related to interferon $\beta$ exposure during pregnancy $(\mathrm{N}=1105) .{ }^{34}$

This is also the first study to report on pregnancy exposure outcomes in black patients with MS. No differences were noted based on race.

Limitations of the Betaseron Pregnancy Registry include the potential for under-reporting or differential 
reporting of outcomes due to the exclusion of retrospective patients. However, it is important to note that data from these retrospective patients were captured through postmarketing surveillance efforts. In addition, birth defect ascertainment was limited to voluntary reports from HCPs (not unlike population-based public health surveillance programmes), which potentially limited the level of detail needed to fully characterise a birth defect case and rule out missed or misdiagnoses. Finally, data on infant outcomes were only collected for up to 4 months, reducing the ability of the registry to measure developmental progress.

Owing to low sample size, definitive conclusions cannot be drawn from the Betaseron Pregnancy Registry data. However, there was no pattern to suggest an increased risk of birth defects in infants or an increased rate of spontaneous abortions in women after exposure to interferon $\beta-1 b$ during pregnancy. Infant assessments, such as birthweight, birth length and head circumference, also did not differ from population estimates and the 4-month infant follow-up did not identify any developmental concerns. Continued monitoring through routine postmarketing surveillance activities is recommended.

\author{
Author affiliations \\ ${ }^{1}$ Department of Neurology, Stony Brook University and MS Comprehensive \\ Care Center, Stony Brook, New York, USA \\ ${ }^{2}$ Clinical Research Program, University of North Carolina Wilmington, \\ Wilmington, North Carolina, USA \\ ${ }^{3}$ Department of Medical Genetics, Tesserae Genetics, Dallas, Texas, USA \\ ${ }^{4}$ Department of Obstetrics and Gynecology, University of North Carolina \\ Schools of Medicine and Public Health, Chapel Hill, North Carolina, USA \\ ${ }^{5}$ Post Approval and Strategic Services, INC Research LLC, Raleigh, \\ North Carolina, USA \\ ${ }^{6}$ Department of Neurology, US Medical Affairs, Bayer HealthCare \\ Pharmaceuticals, Whippany, New Jersey, USA
}

Acknowledgements The authors are grateful to the patients and their healthcare providers for their contributions to the study. Additionally, they thank Robert C Ristuccia, PhD (Precept Medical Communications), for assistance with preparation of the manuscript.

Contributors PKC, MJR and members of the data safety monitoring board, SMS, AES and JMT interpreted data and actively contributed to the writing and reviewing of the submitted manuscript. Member of the data safety monitoring board, JDA provided oversight for the conduct of the study, including the statistical analysis, interpreted data and actively contributed to the writing and reviewing of the manuscript. Sponsor's responsible clinician for registry.

Funding This study was funded by Bayer HealthCare Pharmaceuticals, Inc.

Competing interests PKC has received compensation for consulting/ educational activities from Aconda, Accordant, Bayer, Biogen Idec, Genentech/ Roche, Genzyme/Sanofi Aventis, Merck-Serono, Mylan, Novartis and Teva Neurosciences. She has received research funding from Actelion, Novartis and Opexa. SMS has received compensation for consulting activities from Bayer, Lilly and INC Research. AES has received compensation for consulting activities from Abbott, Amylin, Bayer, Biogen Idec, INC Research, Genentech, Novartis, PPD, TAP Pharma, Roche, Teva and UCB Pharma. JMT has received compensation for consulting from Bayer, GlaxoSmithKline and PPD. JDA is an employee of INC Research, the coordinating centre for the Betaseron Pregnancy Registry. MJR is a salaried employee of Bayer HealthCare.

Ethics approval The Western Institutional Review Board (WIRB) reviewed and approved the protocol, which included a waiver of documentation of informed consent.
Provenance and peer review Not commissioned; externally peer reviewed.

Data sharing statement Some unpublished data remain in the final clinical study report. The data safety monitoring board of the registry (the authors of this paper) decided these data were not necessary for publication.

Open Access This is an Open Access article distributed in accordance with the Creative Commons Attribution Non Commercial (CC BY-NC 3.0) license, which permits others to distribute, remix, adapt, build upon this work noncommercially, and license their derivative works on different terms, provided the original work is properly cited and the use is non-commercial. See: http:// creativecommons.org/licenses/by-nc/3.0/

\section{REFERENCES}

1. Bennett KA. Pregnancy and multiple sclerosis. Clin Obstet Gynecol 2005;48:38-47.

2. Vlahiotis A, Sedjo R, Cox ER, et al. Gender differences in self-reported symptom awareness and perceived ability to manage therapy with disease-modifying medication among commercially insured multiple sclerosis patients. J Manag Care Pharm 2010;16:206-16.

3. Compston A, Coles A. Multiple sclerosis. Lancet 2002;359:1221-31.

4. Coyle PK, Christie S, Fodor P, et al. Multiple sclerosis gender issues: clinical practices of women neurologists. Mult Scler 2004;10:582-8.

5. Betaseron [package insert]. Montville, NJ: Bayer HealthCare Pharmaceuticals, 2010

6. Tysabri [package insert]. Cambridge, MA: Biogen Idec Inc, 2012.

7. Avonex [package insert]. Cambridge, MA: Biogen Idec Inc, 2012.

8. Gilenya [package insert]. East Hanover, NJ: Novartis Pharmaceuticals Corporation, 2012.

9. Copaxone [package insert]. Kansas City, MO: TEVA Neuroscience, 2012.

10. Mitoxantrone [package insert]. Kansas City, MO: TEVA Neurosciences, 2012.

11. Rebif [package insert]. Rockland, MA: EMD Serono, 2012.

12. Aubagio [package insert]. Cambridge, MA: Genzyme Corporation, 2012.

13. Tecfidera [package insert]. Cambridge, MA: Biogen Idec Inc, 2013.

14. Extavia [package insert]. East Hanover, NJ: Novartis Pharmaceuticals Corporation, 2012.

15. US Department of Health and Human Services OoWH. Pregnancy and medicines. http://www.womenshealth.gov/publications/ourpublications/fact-sheet/pregnancy-medicines.pdf (accessed 21 Dec 2012).

16. Covington D, Roberts S, McKain L. Impact of prenatal testing on birth defect prevalence in pregnancy exposure registries. Pharmacoepidemiol Drug Saf 2008;17(Suppl 1):S13.

17. US Food and Drug Administration. Guidance for industry establishing pregnancy exposure registries. http://www.fda.gov/ downloads/ScienceResearch/SpecialTopics/WomensHealth Research/UCM133332.pdf (accessed Feb 2014).

18. Scheuerle A, Tilson $\mathrm{H}$. Birth defect classification by organ system: a novel approach to heighten teratogenic signalling in a pregnancy registry. Pharmacoepidemiol Drug Saf 2002;11:465-75.

19. Jones RK, Kost K. Underreporting of induced and spontaneous abortion in the United States: an analysis of the 2002 National Survey of Family Growth. Stud Fam Plann 2007;38:187-97.

20. Correa A, Cragan J, Kucik J. Metropolitan Atlanta congenital defects program 40th anniversary edition surveillance report: reporting birth defects surveillance data. Birth Defects Res (Part A) 2007;79:65-93.

21. Correa A, Cragan J, Kucik J, et al. Errata. Birth Defects Res (Part A) 2008;82:41-62.

22. U.S.Census Bureau. Overview of race and Hispanic origin: 2010. http://www.census.gov/prod/cen2010/briefs/c2010br-02.pdf (accessed Apr 2013).

23. Jones CA, Pohar SL, Warren S, et al. The burden of multiple sclerosis: a community health survey. Health Qual Life Outcomes 2008;6:1.

24. Kuczmarski RJ, Ogden CL, Grummer-Strawn LM, et al. CDC growth charts: United States. Adv Data 2000;(314):1-27.

25. ACOG Committee Opinion No 579. Definition of term pregnancy. Obstet Gynecol 2013;122:1139-40.

26. Lu E, Wang BW, Guimond C, et al. Disease-modifying drugs for multiple sclerosis in pregnancy: a systematic review. Neurology 2012;79:1130-5.

27. Amato MP, Portaccio E, Ghezzi A, et al. Pregnancy and fetal outcomes after interferon-beta exposure in multiple sclerosis. Neurology 2010;75:1794-802. 
28. Boskovic R, Wide R, Wolpin J, et al. The reproductive effects of beta interferon therapy in pregnancy: a longitudinal cohort. Neurology 2005;65:807-11.

29. Weber-Schoendorfer C, Schaefer C. Multiple sclerosis, immunomodulators, and pregnancy outcome: a prospective observational study. Mult Scler 2009;15:1037-42.

30. Patti F, Cavallaro T, Lo FS, et al. Is in utero early-exposure to interferon beta a risk factor for pregnancy outcomes in multiple sclerosis? J Neurol 2008;255:1250-3.

31. Hellwig K, Haghikia A, Rockhoff M, et al. Multiple sclerosis and pregnancy: experience from a nationwide database in Germany. Ther Adv Neurol Disord 2012;5:247-53.
32. Tomczyk S, Richman S, Wallace K, et al. Final results from the AVONEX (intramuscular-beta-1a) pregnancy exposure registry. Presented at the Annual Meeting of the European Society for Research and Treatment in Multiple Sclerosis; 10-13 October 2012, Lyon, France.

33. Tomczyk S, Sperling B. Post-marketing pregnancy outcomes in patients exposed to intramuscular-interferon-beta-1a. Presented at the Annual Meeting of the European Committee for Treatment and Research in Multiple Sclerosis; 10-13 October 2012, Lyon, France.

34. Hughes S, Spelman T, Gray O, et al. Exposure to interferon-beta therapy in early pregnancy: a literature review of pregnancy outcomes in women with multiple sclerosis. J Neurol Neurosurg Psychiatry 2012;83(Suppl 2): A17. 